\title{
A sexualidade da mulher portadora de deficiência física
}

Fabiano Puhlmann Di Girolamo

\section{IMPORTÂNCIA}

- A mulher portadora de deficiência física pode expressar sua sexualidade de forma saudável e prazeirosa.

- Existem poucos estudos sobre a sexualidade da mulher portadora de deficiência.

- A mulher deficiente esta assumindo sua sexualidade com criatividade sensualidade e autonomia.

- O estudo da vivência sexual da mulher portadora de deficiência, facilita a compreensão da sexualidade total.

- Maior conhecimento sobre sexualidade facilita a mudança de atitudes da mulher portadora de deficiência.

- Implementar a criação de serviços de educação e aconselhamento sexual de mulheres deficientes. 


\section{CONCEITUAÇÃO}

\section{Sexualidade}

Entendemos a sexualidade de forma abrangente considerando sua influência sobre todos os aspectos da vida humana desde a concepção até a morte, manifestando-se em todas as faces da vida (Infância, Adolescência, Fase Adulta, Terceira Idade) sem distinção de raça cor, sexo, deficiências, etc.; considerando a genitalidade como uma de suas formas de expressão, porém não única.

\section{Sexualidade da mulher deficiente}

Existe uma forma especifica de cada mulher reagir aos estímulos sexuais, a mulher portadora de deficiência física é um ser sensível, que tem desejos, e que pode viver com plenitude todas as etapas da relação sexual, (Desejo/Prazer/Orgasmo), apenas alguns tipos de deficiência física (Ex.: lesão raqui-medular) alternam a resposta sexual, sem no entanto impedir uma vivência sexual plena.

\section{Impedimento, deficiência a incapacidade}

lmpedimento: "Qualquer perda ou anormalidade de uma estrutura ou função psicológica, fisiológica ou anatômica".

Ex.: falta um braço, perda dos globos oculares, perda total ou parcial da audição, atrofia muscular de alguma parte do corpo.

Deficiência: "Qualquer restrição ou, falta (resultante de um impedimento) da capacidade de desempenhar uma atividade de uma forma, ou com variação, considerada normal para um ser humano".

Ex.: Deficiência física, visual, auditiva de comunicação, de desenvolvimento, etc.

Incapacidade: "Desvantagem para uma determinada pessoa (resultante de um impedimento ou deficiência), que limita ou impede o desempenho de um papel considerado normal para essa pessoa, dependendo da idade, sexo e fatores sociais e culturais. 


\section{Exemplos de incapacidade}

1. Uma certa pessoa não consegue arranjar um namorado porque aqueles que ela contatou não admitem se relacionar com mulheres portadoras de deficiência.

2. Mulheres em cadeiras de roda não conseguem entrar em danceterias, barsinhos e motéis devido a existência de barreiras arquitetônicas.

3. Mulheres com deficiência mental são impedidas de vivenciar experiências de enamoramento e amor.

4. Uma determinada jovem com deficiência auditiva é superprotegida pela família, que a impede de participar das atividades rotineiras do grupo de adolescentes de seu bairro.

Obs.: O impedimento e a deficiência são fatores endógenos (pessoais). As incapacidades são fatores exógenos (ambientais) já que resultam de atitudes negativistas da sociedade, barreiras arquitetônicas, ambientais e de comunicação.

\section{Histórico do estudo da sexualidade da mulher portadora de defi- ciência}

O estudo da sexualidade do deficiente, apenas nos últimos 10 anos vem sendo encarado de frente, rompendo o mito da assexualidade do deficiente, mesmo profissionais da saúde e reabilitação, apresentam grande dificuldade com relação ao tema, Os poucos estudos publicados referem-se em sua grande maioria às disfunções sexuais dos homens com lesão raqui-medular, existindo raras publicações sobre a sexualidade da mulher portadora de deficiência e também sobre a sexualidade mas demais deficiências (sensoriais, mentais e múltiplas).

No Brasil, a partir do Ano Internacional da Pessoa Deficiente (1981), houve uma implementação do movimento de luta pelos direitos, inclusive de expressão afetivo-sexual de pessoas portadoras de deficiência, destacamos os seguíntes eventos:

- 1980 - Implantação do primeiro Grupo de Orientação sexual da A.A.C.D., trabalho pioneiro da equipe técnica e da psicóloga e paraplégica, Heloísa Chagas.

- Em agosto de 1981 a Comissão estadual de apoio e estímulo ao Desenvolvimento do ano Internacional das pessoas deficientes, de São Paulo, promoveu a Mesa Redonda - Vida afetiva e Sexual de pessoas deficientes, que foi transmitida pela Radio e Televisão Cultura. 
- Realização em novembro de 1981, do I Congresso Brasileiro de Sexualidade da Pessoa Deficiente, em Curitiba.

- Também em 1981 o NID (Núcleo de Integração de deficientes) montou um grupo de discussão sobre a Sexualidade da Pessoa Deficiente e a sua Integração Social.

- Nos últimos cinco anos tem se destacado os serviços prestados pelo CV1 - RJ (Centro de Vida Independente do Rio de Janeiro) a toda a comunidade, incluindo grupos de apoio a sexualidade do deficiente, e trabalho pioneiro de Aconselhamento sexual de pares (onde defícientes treinados facilitam a integração social e sexual de seus iguais).

- Importante contribuição tem silo realizada pelos livros auto biográficos de portadores de deficiência, registrado porém a ausência de publicação seja autobiográficas ou de pesquisa, referentes a vida sexual de mulheres portadoras de deficiência.

\section{Problemas sexuais da mulher portadora de deficiência}

- Dificuldades de se identificar com o padráo estético de beleza adotado pela maioria.

- Preconceitos de homens frente ao fato da mulher ser portadora de deficiência.

- Medos fantasias e mitos que vem a mulher portadora de deficiência física como fragil dependente física e emocionalmente, incapaz de sofrer frustrações,

- Imagem sexual desfavorável veiculada pela Mídia.

- Falta de informação sobre a sexualidade da mulher portadora de deficiência.

- Ausência de serviços de orientação sobre prevenção de D.S.T.

- Auto índice de abuso sexual de mulheres portadoras de deficiência. Vivência de dupla discriminação quando a mulher portadora de deficiência é bissexual ou homossexual.

\section{Auto imagem sexual da mulher portadora de deficiência}

No humano o componente psicossocial, prepondera sobre o aspecto puramente biológico, surgem regras e normas para controlar o comportamento sexual, formando uma cultura e uma ideologia sexual, a mulher 
portadora de deficiência física como toda minoria sobre pressão para enquadrar-se a padrões previamente traçados.

A imagem sexual que a mulher portadora de deficiência tem de si mesma. determinara a forma como vivência sua sexualidade, a auto-imagem, a auto-estima e a imagem corporal são os seus elementos essenciais. Esta imagem interna é fruto de um processo bipolar de retroalimentação, se a mulher deficiente não se sente atraente e digna de ser amada a desejada, provavelmente terá dificuldades em encontrar alguém que consiga perceber estas qualidades nela; pôr outro lado se ela nunca tiver se sentindo refletida nos olhos de alguém, será muito complicado formar uma imagem sexual favorável.

\section{Resposta sexual da mulher portadora de deficiência física}

A resposta sexual da mulher portadora de deficiência física está diretamente ligada a integridade: Gonadal, Endócrina, Neurológica e Psicológica. Seqüelas motora não necessariamente comprometem a função sexual, em termos de função sexual as seqüelas sensoriais são mais importantes do que as motoras.

O desejo sexual está presente na quase totalidade das mulheres portadoras de deficiência física, ocorrendo disfunções deste estágio, na mesma freqüência que em mulheres normais.

Apenas em algumas lesões neurológicos ocorre alteração do mecanismo de resposta sexual (Ex.: Lesões medulares) e mesmo neste tipo de deficiência a mulher é capaz de obter prazer sexual.

\section{Maternidade na portadora de deficiência física}

- A mulher portadora de deficiência física tem o direito a maternidade A mulher portadora de deficiência física pode ter filhos normais já que uma seqüela motora não compromete sua capacidade de procriação.

- Quando gravida a mulher portadora de deficiência física, se depara com a atitude de surpresa e espanto e até revolta das pessoas, que não a percebiam como sexuadas.

- Os centros de reabilitação e demais instituições de saúde não incluem em seus programas um trabalho de planejamento familiar de mulheres deficientes. 
- Os médicos e profissionais de saúde normalmente desestimulam o desejo de engravidar das mulheres portadoras de deficiência.

- A experiência da maternidade da mulher portadora de deficiência física, é única e comum ao mesmo tempo.

- A mulher portadora de deficiência física apresenta os mesmos medos de qualquer mulher frente a fragilidade e dependência do filho, tendo de enfrentar suas limitações físicas e contornar dificuldades operacionais com mais freqüências.

\section{Aconselhamento sexual de pares, e a mulher portadora de deficiência física}

Aconselhamento de pares é um processo dinâmico de orientação, simpatia e encorajamento que uma pessoa tem para com suas iguais, tem como objetivo final o equilíbrio intra-psíquico e equilíbrio pessoa-meio. $\mathrm{O}$ aconselhamento pessoal de pares tem como objetivos específicos: Aumentar a auto estima sexual da mulher portadora de deficiência física. Facilitando o contato com si mesma, e dinaminizando o potencial de auto-ajuda, para que ela descubra as formas de vivênciar sua sexualidade de forma plena dentro de suas reais possibilidades.

A conselheira funciona como ponte melhorando a comunicação afetivo-sexual e reduzindo a ansiedade que a mulher deficiente tenha, relacionada a sexualidade.

$\mathrm{O}$ aconselhamento sexual de uma forma geral deve ser informativo porem não diretivo e baseado nos princípios humanistas e nas estratégias gerais da terapia sexual. Logicamente pressupõe uma preparação previa da conselheira de pares.

\section{Sexualidade e Lesão Medular}

depois de tomar contato com a promiscuidade da fase hospitalar, onde todos tocavam o meu corpo, que parecia nem estar ali, foi que percebi a necessidade e a urgência de resgatá-lo.

Era preciso reconhecê-lo, percebê-lo a acordá lo. Pois jã não dava mais para ficar conivente com sua imobilidade e aparente inércia, e deixá-lo apático e sozinho naquele bordel clínico que a lesão medular estava me impondo.

Era preciso demarcar um limite entre o inevitável e a privacidade do meu corpo que naquele momento saia de seu período assexuado. 
Passei então a fazer daquela nova visão de mim mesma, como pela primeira vez. Não que eu estivesse em condições de perceber o tipo de metamorfose que poderia acontecer, mas definitivamente a lesão medular e a metafísica têm alguma coisa em comum.

Iniciava toques sutis, insistentes que tentavam sintonizar, procurando um outro tom. Comecei ouvindo o ritmo de um coração medroso, teimava batendo num peito passando para trás até um diafragma preguiçoso. Descompassado com minhas pernas que em alum momento achei, não iam mais a lugar nenhum.

Fui aos poucos retornando o controle sobre o meu corpo, conhecendo cada vez mais a questão medular, e então tomou conta um prazer puro, que trouxe orgasmos visuais, táteis, mas que curioso, procurava saber mais e conhecer outros caminhos, outros rumos. Antes que este, aquele, novo, antigo e diferente corpo pudesse novamente se metamorfosear.

\section{Beth Cartano*}

\section{REFERÊNCIAS BIBLIOGRÁFICAS}

1. Reflexão sobre a Condição da Mulher Portadora de Deficiência: A experiência canadense, tradução de Solange Dadalti. In: C.E.D.I.M. (Conselho Estadual dos Direitos da Mulher - RJ.), RJ, 1992.

2. Reflexão sobre a Condição da Mulher Portadora de Deficiência; A experiência brasileira, editado por Sonia Regina Fassini, In: C.E.D.I.M., RJ, 1994.

3. Mulheres deficientes sem limites, de Ana Maria Morales Crespo. In: Revista Claudia, ano, $\mathrm{n}^{\circ} / 89$ pp. 152-154.

4. O deficiente físico na conquista do prazer sexual, de Fabiano Puhlmann Di Girolamo. In: Revista Viver Psicologia, ano 3, n 30. mar/95. pp. 14-15.

* Coordenadora do Setor de Aconselhamento do CVI-RJ. 